\title{
Circulating Proteasome
}

National Cancer Institute

\section{Source}

National Cancer Institute. Circulating Proteasome. NCI Thesaurus. Code C113298.

Cell free proteasome enzyme complexes. Elevated levels of these protein complexes in serum, plasma or blood may be associated with either increased tumor burden or a poor disease prognosis. 